\title{
Pengaruh Metode Pembelajaran Outing Class terhadap Kecerdasan Naturalis Anak Usia 5-6 Tahun
}

\author{
Febriyanti Utami ${ }^{凶}$ \\ Pendidikan Guru Pendidikan Anak Usia Dini, Universitas Sriwijaya \\ DOI: $10.31004 /$ obsesi.v4i2.314
}

\begin{abstract}
Abstrak
Penelitian ini bertujuan untuk melihat adanya pengaruh metode pembelajaran outing class terhadap kecerdasan naturalis anak usia dini. Metode penelitian yang digunakan dalam penelitian ini yaitu experimental design dengan rancangan posttest-only control group design. Penelitian ini dilaksanakan pada anak usia 5-6 tahun (kelompok B) di RA Insani Taqwin Palembang dengan jumlah sampel 32 anak. Teknik pengambilan sampel yang digunakan adalah simple random sampling, dan diperoleh kelas B1 sebagai kelas eksperimen dan kelas B2 sebagai kelas kontrol. Teknik pengumpulan data dilakukan dengan teknik observasi untuk melihat kecerdasan naturalis anak. Analisis data yang digunakan dalam penelitian ini yaitu statistik deskriptif dan statistik inferensial. Uji normalitas dilakukan menggunakan Uji Liliefors dan Uji hipotesis dilakukan menggunakan Uji Bartlett. Pengujian hipotesis dilakukan dengan menggunakan uji-t. Dari hasil perhitungan uji-t yang dilakukan diperoleh $t_{\text {hitung }}=$ $4.32>t_{\text {tabel }}=1,69$, yang berarti $\mathrm{H} 0$ ditolak dan H1 diterima. Dari hasil tersebut dapat disimpulkan bahwa metode pembelajaran outing classmemberikan pengaruh yang signifikan terhadap kecerdasan naturalis anak usia 5-6 tahun di RA Insani Taqwin Palembang.
\end{abstract}

Kata Kunci : metode pembelajaran; outing class; kecerdasan naturalis.

\begin{abstract}
This study aims to see the effect of outing class learning methods on early childhood naturalist intelligence. The research method used in this research is experimental design with posttest-only control group design. This research was conducted in children aged 5-6 years (group B) in RA Insani Taqwin Palembang with a sample of 32 children. The sampling technique used was simple random sampling, and obtained class B1 as an experimental class and class B2 as a control class. The data collection technique is done by observation technique to see the child's naturalist intelligence. Analysis of the data used in this research are descriptive statistics and inferential statistics. Normality test is done using Liliefors Test and Hypothesis testing is done using Bartlett Test. Hypothesis testing is done using t-test. From the results of $t$-test calculations obtained $t$ count $=4.32>t$ table $=1.69$, which means that $\mathrm{H} 0$ is rejected and $\mathrm{H} 1$ is accepted. From these results it can be concluded that the outing class learning method has a significant influence on the naturalist intelligence of children aged 5-6 years at RA Insani Taqwin Palembang.
\end{abstract}

Keywords: learning method; outing class; naturalist intelligence.

Copyright (c) 2020 Febriyanti Utami

$\triangle$ Corresponding author :

Email Address : febriyantiutami@fkip.unsri.ac.id (Palembang Sumatera Selatan, Indonesia)

Received 23 October 2019, Accepted 7 Januari 2020, Published 10 January 2020 


\section{PENDAHULUAN}

Pendidikan anak usia dini merupakan pendidikan yang diselenggarakan untuk memberikan rangsangan atau stimulasi bagi perkembangan anak usia dini secara menyeluruh. Penyelenggaraan pendidikan bagi anak usia dini diciptakan pendidik dengan memperhatikan lingkungan dimana anak dapat bereksplorasi terhadap lingkungannya dan melibatkan seluruh potensi dan kecerdasan anak.

Kecerdasan pada anak usia dini tidak hanya diukur dari aspek kognitif atau intelektualnya. Gardner dalam (Saripudin, 2017: 6)mengemukakan bahwa anak memiliki semua kecerdasan, walau dengan derajat yang beragam. Masing-masing anak memiliki satu kecerdasan dominan dan kecerdasan sekunder yang digunakan dalam menyerap, mengingat dan penerapan pembelajaran. Gardner menyebutkan bahwa kecerdasan tidak bersifat tunggal, tapi majemuk atau disebut kecerdasan majemuk (multiple intelligence). (Jamaris, 2014: 124)Kecerdasan majemuk merupakan kemampuan yang berkembang dari hasil interaksi anak usia dini dan lingkungan di sekitarnya. Kecerdasan majemuk tersebut terdiri dari Kecerdasan Bahasa, Kecerdasan Logika-Matematika, Kecerdasal Visual-Spasial, Kecerdasan Kinestetik, Kecerdasan Musikal, Kecerdasan Intrapersonal, Kecerdasan Interpersonal, dan Kecerdasan Naturalis. (Mufarizuddin, 2017: 63).

Berdasarkan hasil wawancara yang dilakukan oleh orang tua anak uisa 5-6 tahun di RA Insani Taqwin, selama ini orang tua dan pendidik hanya mengukur kecerdasaan seorang anak dari kecerdasan matematika saja, mereka berasumsi bahwa anak yang pintar adalah anak yang pandai dalam matematika. Hal tersebut mengakibatkan kecerdasan lain menjadi terabaikan sehingga tidak terstimulasi dengan maksimal baik di lingkungan rumah maupun di lingkungan sekolah. Seperti yang diungkapkan (Gardner, 2013) setiap anak memiliki kecerdasannya masing-masing, salah satunya yaitu kecerdasan naturalis. Kecerdasan naturalis merupakan salah satu kecerdasan yang harusnya dimiliki oleh anak, karena kecerdasan naturalis merupakan bagian yang tak terpisahkan dari kehidupan di sekitar anak.

Kecerdasan naturalis mempunyai peran yang sangat besar dalam abad yang modern sekarang ini. Pengetahuan anak mengenai alam, hewan, tanaman dapat mengantarkan anak pada profesi yang sesuai dengan kecerdasan yang dimilikinya kelak, kecerdasan naturalis mempunyai peran yang sangat diperlukan dalam menjaga alam ini agar tetap dapat menjaga kelestarianya sehingga dapat dimanfaatkan oleh manusia (Maryanti et al., 2019: 23)

Namun dari hasil observasi yang dilakukan oleh peneliti di RA Insani Taqwin Palemban, pembelajaran yang diterapkan masih berfokus untuk menstimulasi kemampuan anak dalam hal membaca, menulis dan berhitung saja. Dalam proses pembelajaran, di lapangan masih ditemukan guru yang melakukan pembelajaran hanya didalam kelas, bahkan pada tema yang berkaitan dengan lingkungan sekitar. Guru hanya menghadirkan materi-materi dan media yang cukup minim dalam proses pembelajaran di kelas. Hal ini berakibat pada kurang berkembangnya berbagai kecerdasan pada anak usia dini, terlebih pada kecerdasan naturalis anak. Kurang berkembanganya kecerdasan naturalis anak terlihat dari belum pahamnya anak dengan lingkungan sekitar termasuk didalamnya mengenal jenis binatang dan tanaman.

Untuk beberapa tema yang berkaitan dengan lingkungan sekitar, pendidik bisa mengajak anak untuk melakukan kegiatan pembelajaran di luar kelas sehingga anak dapat bereksplorasi secara langsung dengan benda-benda yang dipelajari sesuai dengan materi dan tema yang diajarkan.Metode pembelajaran yang dapat dilakukan di luar kelas salah satunya adalah metode pembelajaran outing class. Pembelajaran outing class berbasis pada keadaan lingkungan sekitar pada tempat tertentu. Metode pembelajaran oouting class dimaksudkan agar anak tidak jenuh dalam pembelajaran, karena selama ini pembelajaran dominan dilakukan di dalam kelas. 
Metode pembelajaran outing class merupakan pembelajaran di luar kelas yang dapat memberikan pengalaman nyata kepada anak agar anak dapat mengkonstruksi pengetahuan baru yang anak dapatkan. Untuk itu peneliti tertarik untuk menerapkan metode pembelajaran outing class dalam proses pembelajaran untuk menstimulasi kecerdasan naturalis pada anak usia dini.

Menurut (Gardner, 2013:17)kecerdasan naturalis adalah kemampuan untuk mengenali, membedakan, mengungkapkan dan membuat kategori terhadap apa yang dijumpai di alam maupun lingkungannya. Dengan kata lain kemampuan untuk mengenali bagian-bagian dari alam semesta.

(Armstrong, 2013)mengemukakan bahwa kecerdasan naturalis adalah expertise in the recognition and classification of the numerios species-the flora and fauna-of an individual's environment. This also includes sensitivity to other natural phenomena (e.g.,cloud formation, mountains, etc) and, in the case of thouse growing up in an urban environment, the capacity to discriminate among inanimate objects such as cars, snearkes, and CD covers. Yang diartikan bahwa kecerdasan naturalis merupakan keahlian dalam mengenali dan mengklasifikasikan berbagai spesies flora dan fauna, dari sebuah lingkungan Individu. Hal ini juga mencakup kepekaan terhadap fenomena alam lainnya (misalnya, formasi-formasi awan, gunung, dll.), dan dalam kasus tumbuh di lingkungan perkotaan, kemampuan untuk membedakkan benda-benda mati seperti mobil, sepatu, dan sampul CD (compact disc).

(Sonawat, 2008 : 85) mengemukakan bahwa seseorang yang memiliki kecerdasan naturalistik ialah individu yang dapat mengenali flora dan fauna beserta hal lainnya yang ada di alam dan menggunakan kemampuannya secara produktif. Sejalan dengan Gündeşli, (2006) yang mengungkapkan bahwa anak yang mrmiliki kecerdasan naturalis, mereka akan tertarik pada berbagai spesies makhluk hidup dan hewan.(Kılıç \& Sert, 2015: 2579).

Dari beberapa pendapat di atas, dapat disimpulkan bahwa kecerdasan naturalis yaitu kemampuan yang dimiliki seseorang dalan mengenali, membedakan, mengungkapkan dan mengklasifikasikan berbagai hal yang ada di alam maupun lingkungannya, seperti flora dan fauna. Kecerdasan naturalis pada anak usia dini dapat dikembangkan dengan berbagai cara, seperti: terlibat di alam terbuka seperti jalan-jalan sambil belajar mengamati tanaman yang dijumpainya, mengamati pemandangan gunung secara langsung, mengamati alam dan makluk hidup, menanam biji-bijian atau penanaman pohon (proses pertumbuhan tanaman, biji-bijian, batang-batangan), menanam bunga, mengamati pertumbuhannya, memelihara, buat gambar metamorfosa kupu-kupu, dan buat papan aneka daun, bercakap-cakap observasi perilaku binatang(Astuti, 2016: 271).

Selain itu kecerdasan naturalis anak dapat dioptimalkan dengan berbagi metode pembelajaran. Salah satunya adalah metode pembelajaran outing class. Hal ini sejalan dengan pendapat (Herwati, 2020: 429) yang menyatakan bahwa anak yang memiliki kecerdasan naturalis lebih senang bermain di luar ruangan. Kecerdasan naturalis perlu ditingkatkan untuk memupuk kepedulian anak dengan alam, sehingga anak akan menyayangi dan menjaga alam.

Metode pembelajaran outing class adalah metode pembelajaran di luar kelas ataupun di luar sekolah dan merupakan salah satu program pembelajaran yang bertujuan memebrikan keterampilan dan keahlian dasar tertentu sebagai sarana menumbuhkan kreativitas anak. Tujuan dari metode pembelajaran outing class yaiu untu meningkatkan semangat belajar anak dan juga memperluas pengetahuan anak. Selain itu metode pembelajaran outing class merupakan suatu kegiatan yang melibatkan alam secara langsung untuk dijadikan sebagai sumber belajar. (Vera, 2012: 17).

(Maulani, 2016: 7)menyatakan bahwa metode pembelajaran outing class adalah salah satu metode pembelajaran yang memiliki manfaat untuk peserta didik dalam belajar, karena dalam model pembelajaran ini anak diajarkan untuk mengenali, peka, dan terjun langsung ke lapangan, seperti di halaman sekolah, taman, kebun dan tempat-tempat lain yang bisa dieksplorasi oleh anak. 
Metode pembelajaran outing class didefinisikan sebagai metode pembelajaran yang dilakukan di luar kelas dengan melibatkan anak secara langsung untuk mengenali dan peka terhadap alam dan lingkungan sekitar.

\section{METODOLOGI}

Penelitian ini merupakan penelitian kuantitatif dengan metode penelitian exsperimental design. Desain penelitian yang digunakan adalah postest only control group design dengan pola berikut:

Tabel 1.Desain Penelitian Postest Only Control Group Design

\begin{tabular}{clcc}
\hline No. & Kelompok & Perlakuan & Postest \\
\hline 1 & Eksperimen & $X$ & T2 \\
2 & Kontrol & - & T2 \\
\hline
\end{tabular}

Penelitian ini dilakukan di RA Insani Taqwin PalembangJl. Sentosa Lr. Keluarga Gg. Mega Mendung No.1237 Rt. 27 Rw. 07 Kec. Seberang Ulu II. Populasi menurut (Sugiyono, 2017: 80)yaitu wilayah generalisasi yang terdiri atas objek atau subyek yang mempunyai kualitas dan karakteristik tertentu yang ditetapkan oleh peneliti untuk dipelajari dan kemudian ditarik kesimpulannya. Populasi dalam penelitian ini adalah seluruh anak dengan rentang usia 5-6 tahun di RA Insani Taqwin yang berjumlah 31 anak yang terdiri dari kelompok B1 berjumlah 16 anak dan kelompom B2 berjumlah 15 anak.Teknik pengambilan sampel yang digunakan dalam penelitian ini yaitu teknik simple random sampling. Teknik simple random sampling dikatakan sederhana karena pengambilan anggota sampel dari polulasi dilakukan secara acak tanpa memperhatikan strata yang ada dalam populasi itu. Teknik simple random sampling memungkinkan setiap unit sebagai unsur populasi meperoleh peluang yang sama untuk menjadi sampel penelitian.

Pada teknik pengambilan sampel ini, peneliti melakukan pengundian untuk menentukan kelompok eksperimen dan kelompok kontrol. Dari hasil pengundian yang dilakukan diperoleh kelompok eksperimen yaitu kelompok B1 dengan jumlah 16 anak dan kelompok kontrol yaitu kelompok B2 dengan jumlah 15 anak. Perlakukan yang diberikan pada kelompok eksperimen berupa pembelajaran dengan menggunakan metode pembelajaran outing class. Sedangkan perlakuan yang diberikan pada kelompok kontrol diberikan perlakuan sama seperti kegiatan sehari-hari di sekolah.

Teknik pengumpulan data yang digunakan dalam penelitian ini berupa instrumen dalam bentuk lembar observasi. Lembar observasi digunakan untuk melihat kecerdasan naturalis anak usia 5-6 tahun. Adapun indikator yang akan diamati pada kecerdasan naturalis anak usia 5-6 tahun diantaranya yaitu, mengenali nama binatang dan tumbuhan, mengungkapkan ciri-ciri binatang dan tumbuhan, mampu mengklasifikasikan binatang dan tumbuhan serta mampu merawat/memelihara binatang dan tumbuhan. Dalam penelitian ini juga menggunakan teknik validasi instrumen lembar observasi kecerdasan naturalis anak. Teknik validasi instrumen yang digunakan yaitu judgment expert.

Teknik analisis data yang dilakukan dalam penelitian ini dilakukan dengan beberapa tahapan, yaitu melakukan perhitungan statistik deskriptif dan dilanjutkan dengan perhitungan statistik inferensial. Perhitungan statistik deskriptik dilakukan untuk mengetahui nilai rata-rata, standar deviasi, range, nilai maksimum dan nilai minimum yang selanjutnya divisualisasikan dengan tabel distribusi frekuensi dan grafik histogram.

Perhitungan statistik inferensial dilakukan untuk uji prasyarat analisis data sebelum dilakukannya uji hipotesis, yaitu uji normalitas dan uji homogenitas data. Uji normalitas data dilakukan dengan uji liliefors. Uji homogenitas data dilakukan dengan uji bartlett dengan taraf signifikansi $\alpha=0,05$. 
Setelah dilakukannya uji prasayarat analisi dilanjutkan dengan uji hipotesis dengan menggunakan uji-t. Pengujian dilakukan dengan taraf signifikansi $\alpha=0,05$ pada taraf kepercayaan $95 \%$.

\section{HASIL DAN PEMBAHASAN}

Data yang digunakan dalam penelitian ini adalah data postest kecerdasan naturalis anak setelah dilakukannya penelitian dengan penerepan metode pembelajaran outing class pada kelas eksperimen dan metode pembelajaran biasa pada kelas kontrol.

Dari hasil perhitungan statistik deskriptif yang dilakukan pada masing-masing kelompok diperoleh nilai rata-rata, stadar deviasi, skor minimum dan skor maksimum yang dituangkan dalam tabel berikut:

Tabel 2. Hasil Perhitungan Statistik Deskriptik Masing-Masing Kelompok

\begin{tabular}{clcc}
\hline No & Perhitungan dari : & $\begin{array}{c}\text { Kelompok } \\
\text { Eksperimen }\end{array}$ & $\begin{array}{c}\text { Kelompok } \\
\text { Kontrol }\end{array}$ \\
\hline 1 & Nilai Rata-rata & 19,44 & 18,80 \\
2 & Standar Deviasi & 2,31 & 2,08 \\
3 & Nilai Maksimum & 24 & 23 \\
4 & Nilai Minimum & 16 & 16 \\
\hline
\end{tabular}

Dari tabel di atas terlihat bahwa nilai rata-rata anak kelompok eksperimen yang diberikan perlakuan dengan metode pembelajaran outing class lebih besar dari nilai rata-rata anak kelompok kontrol yang tidak diberikan perlakuan dengan metode pembelajaran outing class.

Setelah dilakukan perhitungan statistik deskriptif selanjutnya dilakukan perhitungan statistik inferensial untuk menentukan uji normalitas dan uji homogenitas data.

Uji normalitas data dilakukan dengan uji liliefors pada kelompok eksperimen dan kelompok kontrol. Hasil perhitungan uji normalitas yang dilakukan disajikan pada tabel berikut ini:

Tabel 3. Hasil Uji Normalitas Data Masing-Masing Kelompok

\begin{tabular}{clcccc}
\hline No & Kelompok & Jumlah Sampel & L hitung $_{\text { }}$ & L $_{\text {tabel }}$ & Ket. \\
\hline 1 & Ekseprimen & 16 & 0,138 & 0,213 & Normal \\
2 & Kontrol & 15 & 0,183 & 0,220 & Normal \\
\hline
\end{tabular}

Dari tabel di atas, terlihat bahwa data $\mathrm{L}_{\text {hitung }}$ kelompok eksperimen dan data $\mathrm{L}_{\text {hitung }}$ kelompok kontrol lebih kecil dari $\mathrm{L}_{\text {tabel. }}$ Dengan demikian dapat dinyatakan bahwa data kecerdasan naturalis anak dari masing-masing kelompok berdistribusi normal.

Selanjutnya uji homogenitas dilakukan dengan uji bartlett. Hasil perhitungan uji bartlett disajikan pada tabel berikut ini:

Tabel 4. Hasil Uji Homogenitas Data Kelompok Eksperimen dan Kontrol

\begin{tabular}{ccccc}
\hline No & Kelompok & $\mathbf{X}^{2}$ hitung & $\mathbf{X}^{2}{ }_{\text {tabel }}$ & Ket. \\
\hline 1. & Eksperimen \& Kontrol & 0,161 & 3,84 & Homogen \\
\hline
\end{tabular}

Dari tabel di atas, terlihat bahwa $\mathrm{X} 2_{\text {hitung }}$ data kelompok eksperimen dan data kelompok kontrol lebih kecil dar $\mathrm{X} 2_{\text {tabel. }}$. Dengan demikian data kecerdasan naturalis anak dari kedua kelompok tersebut dinyatakan memiliki varians yang sama atau homogen.

Setelah diperoleh data statistik deskriptif dan statistik inferensial, tahap selanjutnya dilakukan uji hipotesis. Uji hipotesis dilakukan dengan uji-t. Berdasarkan hasil perhitungan

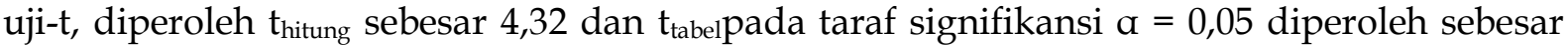


1,69. Dengan demikian, dapat dinyatakan bahwa $t_{\text {hitunglebih }}$ besar dari $t_{\text {tabel, }}$ sehingga hipotesis terdapat pengaruh metode pembelajaran outing class terhadap kecerdasan naturalis pada anak kelompok B di RA Insani Taqwin diterima.

Hal ini diartikan bahwa terdapat perbedaan kecerdasan naturalis yang dimiliki anak usia 5-6 tahun (kelompok B) RA Insani Taqwin antara kelompok eksperimen yang diberi perlakuan dengan metode pembelajaran outing class dan kelompok kontrol yang tidak diberi perlakuan dengan metode pembelajaran outing class.

Hasil penelitian ini juga menjawab permasalahan penelitian ini yaitu terdapat pengaruh metode pembelajaran outing class terhadap kecerdasan naturalis pada anak kelompok B RA Insani Taqwin Palembang. Seperti pendapat Annie R. Hoekstra - de Roos yang menyatakan bahwa kecerdasan naturalis berhubungan dengan sensitifitas seseorang terhadap alam dan semua ditail dan seluk beluknya.(Dwikayani, 2018). Dari hasil observasi pada saat penelitian dilakukan, anak-anak usia 5-6 tahun RA Insani Taqwin terlihat sangat antusias dalam pelaksanaan pembelajaraan outing class sehingga dapat menstimulasi kecerdasan naturalisnya, hal ini ditunjukkan dengan anak-anak usia 5-6 tahun RA Insani Taqwin antusias dan senang ketika melihat binatang dan tumbuhan, anak-anak usia 5-6 tahun RA Insani Taqwin sudah mampu menyebutkan nama-nama binatang dan tumbuhan yang dilihat dengan tepat, anak-anak usia 5-6 tahun RA Insani Taqwin sudah mampu menyebutkan ciri-ciri dari binatang dan tumbuhan yang di lihat, anak-anak usia 5-6 tahun RA Insani Taqwin juga sudah menunjukkan rasa sayang terhadap binatang dan tumbuhan yang mereka lihat

Hasil penelitian ini juga sejalan dengan pendapat Amstrong dalam (Yasbiati, 2017: 207)yang mengungkapkan bahwa cara untuk mengoptimalkan kecerdasan naturalis menggunakan metode-metode pengajaran seperti: akuarium, terrariums, dan ekosistem portabel lainnya, kelas stasiun pemantau cuaca, eco-studi, berkebun, perangkat lunak yang berorientasi alam peralatan untuk mempelajari alam, video, film alam, jalan-jalan di alam terbuka, hewan peliharaan di dalam ruangan kelas, tanaman sebagai alat peraga. Sama hal nya dengan metode pembelajaran outing class. (Juniarti, 2015: 279) juga mengungkapkan dengan mengajak anak berkunjung ke tempat tempat yang memberikan mereka ruang gerak, untuk melakukan eksplorasi hal-hal baru tentang apa saja yang mereka temukan dilingkungan anak-anak dapat mengembangkan kecerdasan naturalis yang dimilikinya.

Metode pembelajaran outing class merupakan salah satu metode pembelajaran alternatif dalam pelaksanaan pembelajaran yang dilakukan di pendidikan anak usia dini. Metode pembelajaran outing class bertujuan untuk menstimulasi kecerdasan naturalis anak. Metode pembelajaran outing class ini juga memberikan manfaat langsung kepada anak terlebih dalam pengenalan alam sekitar yang kaitannya dengan kecerdasan naturalis anak. Merubah cara belajar yang hanya di dalam kelas dengan terjun langsung ke lapangan, seperti di halaman sekolah, taman, kebun, dan tempat-tempat lain yang bisa di eksplorasi. Metode pembelajaran ini menarik perhatian anak karena membuka wawasan mereka tentang lingkungan sekitar dan tidak jenuh dengan pembelajaran di dalam kelas. Menurut Jan Lightghart, sumber utama pembelajaran adalah lingkungan di sekitar anak.(Sunanik, 2018: 89).

Dalam penelitian ini, metode pembelajaran outing class yang dilaksanakan yaitu dengan mengunjungi kebun sekolah dan mengunjungi kandang ternak milik warga yang berada dekat dengan sekolah dalam mengembangkan kecerdasan naturalis yang dimiliki oleh anak seperti mengenalkan binatang dan tumbuhan.(Maulisa, Israwati, \& Amri, 2016) menyatakan Kecerdasan naturalis adalah kemampuan untuk mengenali, membedakan, mengungkapkan dan membuat kategori terhadap apa yang dijumpai di alam maupun lingkungan. Dalam penelitian ini kecerdasan naturalis anak usia 5-6 tahun RA Insani Taqwin yang diamati diantaranya mengenali nama binatang dan tumbuhan, mengungkapkan ciriciri binatang dan tumbuhan, mampu mengklasifikasikan binatang dan tumbuhan serta mampu merawat/memelihara binatang dan tumbuhan. Anak-anak yang mempunyai 
kemampuan dalam mengklasifikasikan dan mengenali binatang dan tumbuhan yang ada di sekitar lingkungannya dapat dikategorikan mempunyai kecerdasan naturalis di dalam dirinya(Rocmah, 2016:48).

Dengan berkembangnya kecerdasan naturalis anak usia 5-6 tahun RA Insani Taqwin, diharapkan pada akhirnya dapat membantu anak mengantarkannya pada kesuksesan dalam hidup. (Ismail, 2018:17) anak yang menunjukkan minat besar terhadap alam, hewan, dan tumbuhan, meskipun itu terkesan kotor dan berbahaya, harus ditempatkan sebagai belajar. Rangsangan yang tepat akan membuat mereka memiliki karier yang luar biasa dalam berbagai bidang di kemudian hari.

Selain itu dengan metode pembelajaran outing class juga dapat menumbuhkan rasa cinta dan kepedulian anak terahadap alam sekitar. (Vera, 2012: 18)juga berpendapat bahwa pembelajaran di luar kelas lebih melibatkan anak secara langsung dengan lingkungan sekitar mereka, sesuai materi yang diajarkan sehingga pembelajaran diluar kelas lebih mengacu pada pengalaman dan pendidikan lingkungan yang sangat berpengaruh pada kecerdasan anak. Agar kecerdasan yang dimiliki oleh anak dapat berkembang secara optimal, potensi bawaan perlu ditumbuhkembangkan melalui berbagai stimulasi dan upaya-upaya dari lingkungan.(Yanti et al., 2014).

Hasil penelitian ini juga didukung dengan hasil penelitian yang telah dilakukan oleh (Maryanti et al., 2019: 30)yang menyatakan bahwa metode outing class dapat meningkatkan kecerdasan naturalis anak usia dini. Hal ini diperkuat dengan hasil penelitian tindakan yang dilakukan, teradapat peningkatan kecerdasan naturalis pada siklus I $70 \%$ menjadi $82 \%$ pada siklus II.

\section{SIMPULAN}

Terdapat perbedaan kecerdasan naturalis anak antara kelompok eksperimen yang diberi perlakuan dengan metode pembelajaran outing class dengan kelompok kontrol yang tidak diberi perlakuan dengan metode pembelajaran outing class. Perbedaan ini ditunjukkan dengan skor rata-rata kecerdasan naturalis yang diperoleh anak pada masing-masing kelompok. Skor rata-rata kecerdasan naturalis anak pada kelompok eksperimen lebih besar dari skor rata-rata kecerdasan naturalis anak pada kelompok kontrol. Terdapat pengaruh penerapan metode pembelajaran outing class terhadap kecerdasan naturalis anak usia dini pada kelompok B RA Insani Taqwin Palembang.

\section{UCAPAN TERIMAKASIH}

Peneliti mengucapkan kepada Kepala Sekolah dan Guru Kelas B RA Insani Taqwin Palembang, yang sudah memberikan izin dan bantuan kepada peneliti dalam melaksanakan penelitian di RA Insani Taqwin Palembang.

\section{DAFTAR PUSTAKA}

Armstrong, T. (2013). Kecerdasan Multiple Di Dalam Kelas. Jakarta: PT Indeks.

Astuti, W. T. (2016). Pembelajaran Anak Usia Dini Berbasis Multiple Intelligences di TK Tunas Harapan Tambakrejo Ngaglik Sleman. 1(November), 257-276.

Dwikayani, Y. (2018). Meningkatkan Kecerdasan Naturalis Anak melalui Kegiatan Berkebun (Penelitian Tindakan di TK B Embun Pagi Islamic School Kalimalang Jakarta Timur Tahun 2015). Jurnal Tumbuh Kembang : Kajian Teori Dan Pembelajaran PAUD, 5(1).

Gardner. (2013). Multiple Intelligences (Memaksimallkan Potensi \& Kecerdasan Individu dari Masa Kanak-Kanak Hingga Dewasa). Terjemahan Yelvi Andri Zaimur. Jakarta: Darras Books.

Herwati, Y. (2020). Jurnal Obsesi : Jurnal Pendidikan Anak Usia Dini Pengaruh Permainan Ludo Adventure terhadap Kecerdasan Naturalis Anak Usia Dini Abstrak. 4(1), 428-437. https://doi.org/10.31004/obsesi.v4i1.358 
Ismail, A. (2018). Pengembangan Instrumen Kecerdasan Naturalis Anak Usia Dini Di Kabupaten Luwu Timur Provinsi Sulawesi Selatan. Jurnal Evaluasi Pendidikan, 9(1), 1629.

Jamaris, M. (2014). Pengembangan Instrumen Baku Kecerdasan Jamak Anak Usia Dini. PARAMETER: Jurnal Pendidikan Universitas Negeri Jakarta, 25(2), 123-137. https://doi.org/10.21009/parameter.252.08

Juniarti, Y. (2015). Peningkatan kecerdasan naturalis melalui metode kunjungan lapangan (field trip). Jurnal Pendidikan Usia Dini, 9(2), 267-284.

Kılıç, M. S., \& Sert, H. (2015). Primary School 5th Grade Science and Technology Lesson Book's Investigation of Multiple Intelligence Theory. Procedia - Social and Behavioral Sciences, 174, 2577-2581. https:// doi.org/10.1016/j.sbspro.2015.01.935

Maryanti, S., Kurniah, N., \& Yulidesni, Y. (2019). Meningkatkan Kecerdasan Naturalis Anak Melalui Metode Pembelajaran Outing Class Pada Kelompok B Tk Asyiyah X Kota Bengkulu. Jurnal Ilmiah POTENSIA, 4(1), 22-31. https:/ / doi.org/10.33369/jip.4.1.22-31

Maulani, L. N. (2016). Pelaksanaan Model Pembelajaran Outing Class Pada Kelas Melukis Anak Di Lembaga Sosial Masyarakat Rumah Hebat Indonesia, Banjarsari, Surakarta. Universitas Sebelas Maret.

Maulisa, R., Israwati, \& Amri, A. (2016). Meningkatkan Kecerdasan Naturalis Anak Melalui Media Bahan Alam. Jurnal Ilmiah Mahasiswa PAUD, 1(1), 1-14.

Mufarizuddin. (2017). Peningkatan kecerdasan logika matematika anak melalui bermain kartu angka kelompok B di TK Pembina Bangkinang Kota. Faktor-Faktor Yang Berhubungan Dengan Perkembangan Bahasa Balita Di UPTD Kesehatan Baserah, 1(2), 148155. https:// doi.org/10.31004/obsesi.v1i1.32

Rocmah, L. I. (2016). Peningkatan Kecerdasan Naturalis Melalui Bermain Messy Play terhadap Anak Usia 5-6 Tahun. PEDAGOGIA: Jurnal Pendidikan, 5(1), 47. https://doi.org/10.21070/pedagogia.v5i1.88

Saripudin, A. (2017). Strategi Pengembangan Kecerdasan Naturalis Pada Anak Usia Dini. AWLADY: Jurnal Pendidikan Anak, 3(1). https://doi.org/10.24235/awlady.v3i1.1394

Sonawat, R. \& P. G. (2008). Multiple Intillegence for Presschool Children. Mumbai: Multi-Tech Publishing co, fist edition.

Sugiyono. (2017). Statistik Untuk Penelitian. Bandung: Alfabeta.

Sunanik. (2018). Pembelajaran Berbasis Alam untuk Anak Usia Dini di TK Alam Al-Azhar Kutai Kartanegara. Jurnal Ilmiah AL-MADRASAH, 3(1). https://doi.org/10.35931/am.v0i0.71.

Vera, A. (2012). Metode Mengajar Anak di Luar Kelas (Outdoor Study). Jogjakarta: DIVA Pres.

Yanti Yulie Eka; M. Thamrin; Mawarni R. (2014). Mengembangkan Kecerdasan Naturalis Tentang Lingkungan Prasekolah Anak Usia 5-6 Tahun TK LKIA III Pontianak. Jurnal Pendidikan Dan Pembelajaran Khatulistiwa, 3(3).

Yasbiati, dkk. (2017). Upaya Meningkatkan Kecerdasan Naturalis Melalui Kegiatan Bercocok Tanam di BAMBIM Al-Abror Kecamatan Mangkubumi Kota Tasikmalaya. Jurnal PAUD Agapedia, 1(2). 